\title{
Direito à saúde: demanda por suplementos no Tribunal de Justiça
}

\author{
The right to health: a demand for supplements in the Court of Justice
}

Derecho a la salud: demanda por suplementos ante Tribunal de Justicia

Elen Petean ${ }^{1}$, Laura Filomena Santos Araújo², Roseney Bellato ${ }^{3}$, Carla Gabriela Wunsch ${ }^{4}$, Leandro Felipe Mufato ${ }^{5}$, Marly Akemi Shiroma Nepomuceno ${ }^{6}$

\section{RESUMO}

Buscou-se compreender como o Tribunal de Justiça de Mato Grosso contribui na efetivação do direito à saúde, ao atuar como mediador na demanda de pessoas e/ou famílias por suplementos. Objetivou conhecer a origem, o motivo, o objeto, o sujeito demandante e a resolutividade das decisões judiciais. Trata-se de estudo qualitativo baseado em pesquisa documental. Das 28 decisões analisadas, 92,8\% (26) demandaram compostos alimentares e 7,1\% (2), fitas de controle glicêmico. 0 magistrado acolheu o pedido em $96,5 \%$ (27) das decisões, recorrendo estritamente à Constituição Federal, em seu discurso sobre o direito à saúde, e à prescrição médica como prova jurídica. Tais prescrições impõem marcas comerciais em $100 \%$ (28) dos casos, e a alergia alimentar pediátrica constitui principal motivo da demanda, 17,8\% (5). A maioria dos adoecimentos, considerados condições crônicas de saúde, demanda cuidados continuados e prolongados, frente aos quais o caráter pontual das decisões judiciais pouco contribui para efetivação da equidade e integralidade em saúde.

Descritores: Direito à saúde; Decisões judiciais; Doença Crônica; Suplementos Dietéticos.

\section{ABSTRACT}

This study aimed at understanding how the Mato Grosso Court of Justice contributes to the right to health, by working as the mediator for the demands of people and/or families for supplemental health care. The objective was to identify the origin, reason, object in demand and the subject making the request, as well as determining how the demand was resolved in regards to the legal decision made. This qualitative study is based on documental research. Of the 28 analyzed decisions, $92.8 \%$ (26) requested food, and $7.1 \%$ (2) required glucose test strips. The judge endorsed the request in $96.5 \%$ (27) of the cases, referring to the Federal Constitution in the discourse regarding the right to health, and using the medical prescription as legal evidence. The referred prescriptions mention commercial brands in $100 \%$ (28) of the cases, and pediatric food allergy is the main reason for the demand (17.8\%) (5). Most diseases considered to be chronic health conditions demand continuous and prolonged care, and the timely character of legal decisions do not contribute much to the equality and comprehensiveness of health care.

Descriptors: Right to Health; Judicial Decisions; Chronic Disease; Dietary Supplement.

\section{RESUMEN}

Se buscó comprender cómo el Tribunal de Justicia de Mato Grosso contribuye en la efectivización del derecho sanitario, actuando como mediador en demandas de personas y/o familias por suplementos. Se objetivó conocer origen, motivo, objeto, sujeto demandante y resolutividad de los fallos. Estudio cualitativo basado en investigación documental. De 28 fallos analizados, 92,8\% (26) demandaron complementos alimentarios y 7,1\% (2) cintas de control glucémico. El magistrado acogió el pedido en 96,5 (27) de sus fallos, recurriendo estrictamente a la Constitución Federal en su discurso sobre derecho a la salud, y a la prescripción médica como prueba jurídica. Tales prescripciones imponen marcas comerciales en 100\% (28) de los casos; alergia alimentaria pediátrica constituyó principal motivo de demanda, 17,8\% (5). La mayoría de padecimientos, considerados condiciones crónicas de salud, demanda cuidados continuos y prolongados; frente a ellos, el carácter puntual de los fallos poco contribuye para efectivizar equidad e integralidad en salud.

Descriptores: Derecho a la Salud; Decisiones Judiciales; Enfermedad Crónica; Suplementos Dietéticos.

\footnotetext{
${ }^{1}$ Acadêmica do curso de Graduação em Enfermagem, Faculdade de Enfermagem (FAEN), Univesidade Federal do Mato Grosso (UFMT). Cuiabá, MT, Brasil. E-mail: elenpetean@yahoo.com.br.

2 Enfermeira, Doutora em Enfermagem, Professora Adjunto, FAEN, UFMT. Cuiabá, MT, Brasil. E-mail: laurafil1@yahoo.com.br.

${ }^{3}$ Enfermeira, Doutora em Enfermagem, Professora, FAEN, UFMT. Cuiabá, MT, Brasil. E-mail: roseney@terra.com.br.

4 Enfermeira, Discente do Programa de Pós-Graduação em Enfermagem - nível Mestrado, FAEN, UFMT. Cuiabá, MT, Brasil. E-mail: carlagabi20@hotmail.com.

5 Enfermeiro, Discente do Programa de Pós-Graduação em Enfermagem - nível Mestrado, FAEN, UFMT. Cuiabá, MT, Brasil. E-mail: leandro.mufato@yahoo.com.br.

${ }^{6}$ Enfermeira, Discente do Programa de Pós-Graduação em Enfermagem - nível Mestrado, FAEN, UFMT, Enfermeira da Secretaria Estadual de Saúde do Mato Grosso. Cuiabá, MT, Brasil. E-mail: marlynepo1@yahoo.com.br.
} 


\section{INTRODUÇÃO}

Este estudo está inserido em uma pesquisa matricial que pretendeu compreender como as Instituições Jurídicas têm contribuído na efetivação do direito à saúde, ao atuar como mediadoras formais modificando Itinerários Terapêuticos (ITs) de usuários e suas famílias, em busca de cuidados no contexto do Sistema Único de Saúde (SUS) em Mato Grosso.

Como parte dessa pesquisa, buscou compreender como o Tribunal de Justiça do Estado de Mato Grosso (TJMT), tem contribuído na efetivação do direito à saúde de pessoas e/ou famílias que vivenciam um adoecimento, ao atuar como mediador na demanda dessas pessoas por suplementos no contexto do SUS/MT. Neste estudo entendeu-se por suplementos os compostos alimentares especiais, ou seja, fórmulas lácteas, bem como insumos indispensáveis para a saúde, no caso, fitas para aferição de glicemia capilar. Sua pertinência e relevância se mostram ao permitir compreender alguns aspectos da chamada "judicialização da saúde", possibilitando repensar aspectos fundamentais, da demanda e mediação jurídica, que possam contribuir para a concretização do direito à saúde, garantido pela Constituição Federal (CF) e Lei Orgânica da Saúde, mas não consubstanciado de fato.

Trata-se de um dos principais direitos conhecidos no Brasil, tendo importante destaque na CF, que define saúde como um direito social fundamental, de caráter universal, que deve ser assegurado pelo Estado e efetivado por intermédio de políticas sociais e econômicas $^{(1)}$. A Lei $n^{\circ} 8.080$ de 19 de setembro de 1990, reafirma a saúde como um direito fundamental do ser humano, devendo o Estado prover as condições indispensáveis para seu exercício integral, através da reformulação e execução de políticas econômicas e sociais ${ }^{(2)}$.

Dentre as condições indispensáveis, no tocante a este estudo, destaca-se a Política Nacional de Alimentação e Nutrição, recentemente atualizada pela Portaria $n^{\circ} 2.715$, de 17 de novembro de 2011, segundo a qual, para a afirmação plena dos potenciais de crescimento e desenvolvimento do ser humano, a alimentação e nutrição são requisitos básicos, necessários para uma vida com qualidade e garantia de

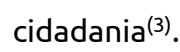

A Portaria $n^{\circ}$ 2.583, de 10 de outubro de 2007, também contempla outra questão relevante para o estudo, pois define o elenco de medicamentos e insumos disponibilizados pelo Sistema Único de Saúde (SUS) aos usuários com Diabetes Mellitus (DM). Baseada nos termos da Lei $n^{\circ} 11.347$ de 27 de setembro de 2006, afirma que estes insumos, destinados ao monitoramento da glicemia capilar das pessoas com este agravo devem ser disponibilizados, gratuitamente, sendo eles, as seringas com agulha acoplada para aplicação de insulina, as tiras reagentes de medida de glicemia capilar e lancetas para punção digital(4-5).

Apesar de a saúde ser reconhecida constitucionalmente como dever do Estado, e haver leis, portarias e políticas que garantem à população a distribuição dos suplementos demandados neste estudo, ainda há casos em que esse direito, por algum motivo, não é efetivado. Uma das justificativas do Estado para a não garantia desse direito é a indisponibilidade de recursos financeiros; porém, as iniquidades em saúde relacionadas aos recursos vão além de sua escassez, pois, no Brasil, grupos mais vulneráveis são diretamente afetados com a má gestão na distribuição desses recursos ${ }^{(6)}$.

Sendo assim, o cenário atual das desigualdades e iniquidades em saúde no Brasil está determinado por uma distribuição inadequada das riquezas, que afeta diretamente as pessoas ${ }^{(7)}$. Nesse panorama, o Poder Judiciário tem desempenhado a função de mediador no cumprimento do direito da população sendo foco deste estudo, a mediação realizada pelo TJMT.

Deste modo, o objetivo do presente estudo foi conhecer a demanda de garantia do direito à saúde no TJMT, em relação aos compostos alimentares especiais e insumos, verificando a origem, o motivo, o objeto da demanda, quem é o sujeito demandante e a resolutividade das decisões judiciais para as pessoas/e ou famílias.

\section{METODOLOGIA}

Trata-se de um estudo com base qualitativa e foco em pesquisa documental, que consiste na coleta, seleção e utilização de toda informação, tendo como documento, todo escrito, manuscrito ou impresso, o qual é considerado memória, sendo uma fonte valiosa do testemunho de uma atividade particular ${ }^{(8)}$. Analisaram-se documentos de demandas judiciais originárias de um arquivo de domínio público, sendo disponibilizados os 
relatórios das decisões judiciais, em formato de arquivo PDF.

A coleta deu-se de abril a junho de 2010, por via online, no endereço eletrônico (http://www.tjmt.jus.br/) do TJMT, que após investigação preliminar, definiu-se as seis Câmaras Cíveis e duas Turmas de Câmaras Cíveis para objeto do estudo no campo da câmara julgadora. Após acesso ao site foi necessário percorrer pelo link "serviços", em seguida "jurisprudências". Sendo indispensável o preenchimento de "campos" dentro dos itens "jurisprudência" e "pesquisa por dados da jurisprudência", que determinam o refinamento desses documentos.

De modo que as opções selecionadas foram:

- Colegiado, marcado a opção "tribunal de justiça", por ter abrangência genérica;

- Tipo de pesquisa, "por dados da jurisprudência" que abrange todas as decisões do período escolhido;

- Local da pesquisa, "inteiro teor", onde as palavras-chave são localizadas em toda extensão da decisão, e não apenas na ementa;

- Filtro de pesquisa, usado o descritor "direito a saúde" para que fosse possível refinar a área da saúde dentre os diversos campos do direito cível;

- Magistrado, selecionado "todos" e "incluir magistrados aposentados", para selecionar todos que estiveram à frente do julgamento no período delimitado;

- Data do julgamento, o período de "01/04/2008 a 31/03/2009", delimitando-se o período de um ano em relação às decisões selecionadas, bem como ao período de início da coleta de dados para pesquisa. Este último critério permitiria visualizar a repercussão das ações judiciais para pessoas e famílias que vivenciam uma condição crônica, um dos objetivos do projeto matricial;

- Classe, "mandado de segurança e mandado de segurança coletivo", por serem os mecanismos processuais comumente usados por usuários.

O resultado da busca totalizou 346 decisões judiciais, das quais, excluídos os documentos duplicados, restaram 338. Foi realizada uma leitura atenta, identificando elementos possíveis de análise em sua estrutura e composição, o que permitiu uma pré- categorização ao identificar, no texto, palavras e expressões significativas ${ }^{(9)}$.

Uma tabela descritivo-analítica, em formato Excel foi produzida que, após discussões e análises feitas pelo grupo da pesquisa, sofreu modificações/contribuições, resultando em sete planilhas. A primeira com os dados gerais de identificação das decisões (APÊNDICE A) e as demais com os tipos de demanda visualizadas nesta primeira leitura: medicação (APÊNDICE B), cirurgia, múltiplas demandas, unidade de terapia intensiva, transporte e transplante.

O preenchimento dessas planilhas, com decisões por Câmaras Julgadoras, foi executado pelo grupo, de modo a esgotar todas as informações contidas nos documentos. Em seguida, houve a junção de todas as Câmaras em uma única tabela. A partir daí, o processo de análise dos dados foi redistribuído em tabelas do Excel por "categoria de demanda", entre os alunos de iniciação científica e mestrandos/enfermeiros.

Como forma de organização, nesse momento de tratamento e analise, a categoria Medicamentos, por ser a mais numerosa (200 decisões), foi dividida em três subcategorias, sendo desmembrados em "Medicamentos nomeados para câncer", "Outros medicamentos" e "Suplementos". Sendo este último o objeto deste estudo, contendo 30 decisões judiciais, que após passarem por um processo de validação, duas decisões foram consideradas múltiplas demandas, restando, deste modo, 28 decisões judiciais analisadas neste estudo.

Para analisá-las, cada coluna da tabela, com cada decisão organizada por número de ordem (considerando a ordem do total da busca, ou seja, de 1 a 338), foi separada e nomeada por uma letra - O que está sendo demandado nomeou-se pela letra (A), Adoecimento (B), Alegação do autor (C), Alegação do Réu/representante (D), Julgamento do juiz, motivo da negativa (E) e Julgamento do juiz, motivo da concessão pela letra (F). Realizou-se então um processo de descrição quantiqualitativa dos dados que facilitou o procedimento de análise a partir de revisões bibliográficas pertinentes ao assunto, as quais embasaram e permitiram as discussões.

O projeto matricial à qual se vincula este estudo foi aprovado pelo Comitê de Ética em Pesquisa com Seres Humanos do Hospital Universitário Julio Muller (HUJM), sob o $n^{\circ}$. 671/CEP-HUJM/2009. Embora os documentos analisados sejam de domínio público, os nomes dos sujeitos nomeados nas decisões foram mantidos em 
sigilo na divulgação deste trabalho, respeitando-se o princípio do anonimato.

\section{RESULTADOS E DISCUSSÕES}

O direito à saúde no Brasil tem se resumido a uma concepção de acesso aos bens e serviços de saúde, que quando não concretizado, leva a população a recorrer ao Poder Judiciário como estratégia para sua garantia(10), muitas vezes de maneira individual, aspecto esse, confirmado neste estudo. As decisões judiciais analisadas são compostas, de maneira geral, pela ementa que trata do resumo da ação judicial; o corpo das decisões judiciais que contém os relatórios, trazendo os votos de magistrados em relação ao recurso, e o Acórdão, que traz a decisão com os votos dos diferentes magistrados.

Foram analisadas 28 decisões, das quais o agravo de instrumento, um tipo de recurso utilizado no direito, apareceu em 89,2\% (25), a apelação cível em 7,1\% (2) e o mandado de segurança em 3,5\% (1). Em relação à autoria, $82,1 \%$ (23) das decisões tiveram como autor o Estado de MT, que nesse caso por se tratar de um agravo de instrumento, são decisões judiciais ocorridas em segundo grau, ou seja, o Estado de MT recorre da decisão do magistrado com objetivo de contrapor uma determinação judicial dada na $1^{\text {a }}$ Instância, para que o pedido do usuário não seja atendido.

Nos outros $17,8 \%$ (5) o autor foi o próprio usuário, em que $3,5 \%$ (1) das ações propostas, são originadas no próprio TJMT, ou seja, o usuário entra demandando judicialmente já em $2^{a}$ Instância, como é o caso do mandado de segurança. Concernente aos outros $14,2 \%$ (4) de decisões emanadas na $2^{a}$ Instância, ainda que a autoria seja o próprio usuário, tratou-se de recursos de origem em $1^{\text {a }}$ Instância.

Do total das análises, 92,8\% (26), o magistrado conferiu a negativa do recurso ao Estado de MT, isso significa que the foi negado o pedido de não fornecer ao usuário o suplemento demandado; em 7,1\% (2) foi dado o provimento parcial do recurso, um deles o magistrado apenas conferiu ao Estado a redução da multa, pois entendeu que ela não deve representar um custo exagerado que possa prejudicar o cumprimento de outras obrigações:
Dou parcial provimento ao recurso tão somente para reduzir o quantum da multa diária em caso de descumprimento de $R \$ 1500,00$ para $R \$ 750,00$ (F-10).

Em outro, o pedido por compostos alimentares não foi atendido, nos termos:

Desprovejo, porém, o pedido de imposição de fornecimento do complemento alimentar indicado nos autos (F-70).

São várias as justificativas do magistrado para negativa desse pedido, mas o argumento jurídico principal foi a condição financeira da pessoa/família:

[...] certo é que a imposição do seu fornecimento gratuito ao Município depende da demonstração da dificuldade financeira dos pais do menor na aquisição do bem (F-70).

O usuário teve seu pedido atendido em 96,5\% (27) das decisões, no caso acima o magistrado não aceitou o pedido do usuário por entender que este era capaz de arcar com o custo do seu tratamento:

No caso, não há dúvida que os pais da criança que se pretende tutelar possuem boa condição financeira, tanto que, como apontado na sentença, residem no bairro mais luxuoso da cidade [...] presume-se que tenham condições de arcar com os custos atinentes ao alimento pretendido (F-70).

Nesta ação, o argumento do magistrado para negar provimento ao direito resvalou, supostamente, na acepção do princípio de equidade, que seria oferecer direitos iguais a todos e, ao mesmo tempo, não retirar direitos, apenas respeitar as necessidades de cada um e tratar as diferenças oferecendo um tratamento desigual para superar as desigualdades, não no sentido de privar alguns de seus direitos, mas de garantir uma igualdade de condições, procurando dar mais prioridade aquele mais desprovido ${ }^{(6-7)}$ :

Não se trata de discriminação de pessoas que tenham boa condição econômica, tal como se o direito à saúde não thes fosse assegurado (F-70).

Desta forma, o magistrado entende que os gastos gerados para o município irão causar danos aos recursos 
destinados a saúde, já que a fórmula alimentar demandada não consta no orçamento municipal. Assim ele considera essa concessão inviável, já que, se obrigasse o município a fornecer o suplemento solicitado, seria para atender apenas a necessidade de uma pessoa, e não da coletividade:

[...] dos recursos municipais destinados à saúde pelo menos $R \$ 14.400,00$ (catorze mil e quatrocentos reais) seriam anualmente gastos com apenas uma pessoa [...]. Desta forma, como não há demonstração de impossibilidade dos pais arcarem com o pagamento dos custos do alimento buscado, impossivel a imposição do seu fornecimento ao Município (F-70).

Verifica-se, no entanto, que a percepção do magistrado em relação ao direito à saúde nesse documento difere da encontrada nas demais decisões (27), nas quais importa que saúde é um direito de todos conforme a CF e, portanto, obrigação do estado garantir que isso se efetive ${ }^{(1)}$ :

Verifica-se, portanto, que o direito à saúde deve ser assegurado, sem distinção, a todos os cidadãos, sendo obrigação do Estado fornecer condições a seu pleno exercício, incluindo o fornecimento gratuito de medicamentos (E-69).

Percebe-se que o Poder Judiciário, na maior parte de suas decisões, apoiou-se basicamente na CF, entendendo que o direito da pessoa deve ser garantido acima de qualquer argumento, mesmo no fato do objeto da demanda não constar no orçamento público ou nas portarias estaduais e municipais, sendo baseada na lei, não levando em consideração a repercussão do seu voto para o SUS:

[...] a linha argumentativa desenvolvida de inexistir previsão orçamentária para fazer a obrigação trazida a lume pela decisão recorrida não é motivo suficiente para impedir o fornecimento do medicamento, pois é indispensável à saúde do agravado. Nesse particular, incide o princípio da proporcionalidade e/ou razoabilidade, [...] devendo-se prestigiar o direito à saúde em detrimento da condição financeira do Estado (E-2).
Em relação à origem da demanda (Tabela 1), em $60,7 \%$ (17) a capital Cuiabá foi o local onde mais se originaram demandas. Isso pode ocorre por concentrar a maior população do estado e pelo fato das instituições jurídicas estarem mais acessíveis para essa população. Porém, deve-se considerar que se trata de uma amostra (28) em que os resultados foram obtidos com rigor metodológico que a delimitaram.

Tabela 1: Origem da demanda por suplementos, Mato Grosso, 2008-2009.

\begin{tabular}{ccc}
$\begin{array}{ccc}\text { Comarcas de origem da } \\
\text { demanda }\end{array}$ & Número de decisões & $\%$ \\
\cline { 1 - 2 } Capital (Cuiabá) & 17 & 60,7 \\
Tangará da Serra & 5 & 17,8 \\
Várzea Grande & 3 & 10,7 \\
Alta Floresta & 1 & 3,5 \\
Rondonópolis & 1 & 3,5 \\
Matupá & 1 & 3,5 \\
\hline Total & $\mathbf{2 8}$ & $\mathbf{1 0 0}$ \\
\hline
\end{tabular}

Sobre o objeto de demanda (Tabela 2), a maioria $92,8 \%$ (26) foram os compostos alimentares, basicamente leites especiais ou compostos usados em casos específicos; além disso, fitas de controle glicêmico representaram $7,1 \%$ (2) e também foram objetos de demanda:

Tabela 2: Objeto da demanda nas decisões judiciais, Mato Grosso, 2008-2009.

\begin{tabular}{ccc}
\cline { 1 - 2 } Objeto da demanda & Número de decisões & $\%$ \\
\cline { 1 - 2 } Leite Nutren Júnior & 5 & 17,8 \\
Leite Nan Soy & 5 & 17,8 \\
Leite Alfaré & 3 & 10,7 \\
Leite Nan-sem lactose & 3 & 10,7 \\
Fitas reagentes-controle & 2 & 7,1 \\
glicêmico & 1 & 3,5 \\
Leite Pregomin & 1 & 3,5 \\
Leite Nan I PRO & 1 & 3,5 \\
Leite PKU 2 & 1 & 3,5 \\
Leite PKU 3 & 1 & 3,5 \\
Reabilit Immubo & 1 & 3,5 \\
Neocate & 1 & 3,5 \\
Alitraq & 1 & 3,5 \\
Pediasure & 1 & 3,5 \\
Modulen & 1 & 3,5 \\
"suplemento alimentar" & $\mathbf{2 8}$ & $\mathbf{1 0 0}$
\end{tabular}

[...] concedeu a antecipação de tutela vindicada pelo autor, determinando o fornecimento de fitas reagentes para controle glicêmico (A-223). 
Salienta-se a importância da análise dessas demandas por fitas glicêmicas, visto que o DM é uma doença crônica caracterizada pelo comprometimento do metabolismo da glicose, cujo controle inadequado resulta no aparecimento das graves complicações que reduzem a expectativa e qualidade de vida. As intervenções terapêuticas do Diabetes Mellitus visam o rigoroso controle glicêmico, por meio de automonitoramento da glicemia capilar, que contribui para uma participação mais ativa do usuário no seu tratamento, promovendo estímulo a um melhor acompanhamento da doença, contribuindo para reduzir às complicações e consequentemente as internações. $O$ monitoramento deve ser feito de três a quatro vezes ao dia, para um tratamento adequado $(4,11)$.

Além disso, é preciso considerar que já existe uma distribuição desses insumos pelo Ministério da Saúde, através do Programa Nacional de Assistência Farmacêutica para Hipertensão Arterial e Diabetes Mellitus, criado por meio da Portaria n 371/GM em 04 de março de $2002^{(12)}$. Sendo ainda, reafirmada a distribuição gratuita desses insumos pela Lei $n^{\circ} 11.347$ de 27 de setembro de 2006, que dispõe sobre a distribuição gratuita de medicamentos e materiais necessários à sua aplicação e à monitoração da glicemia capilar às pessoas inscritas em programas de educação para diabéticos, assim, o SUS deve fornecer os insumos necessários ${ }^{(5)}$.

Estas duas demandas foram geradas na capital Cuiabá, tendo como data de julgamento os meses de agosto e novembro do ano de 2008. O município começou a distribuir esses insumos apenas em outubro de 2009, depois de ser notificado com uma ação recomendatória de processo preliminar 001507002/2006 do Ministério Público, pois não estava realizando a distribuição dos insumos.

Relativo ao outro objeto da demanda verificou-se que nas decisões judiciais dos compostos alimentares, $42,3 \%$ (11) não relataram a quantidade requerida do insumo:

Concedeu tutela antecipada determinando que 0 Agravante forneça ao menor V.H., que conta com 11 meses de idade, o Leite Nan Soy (A-21).

Isso leva-nos a acreditar que as decisões judiciais são pouco resolutivas e pontuais, pois como já descrito a maioria dos agravos são crônicos e necessitariam de um tratamento constante bem como uma regularidade na distribuição dos insumos.

Enquanto $38,4 \%$ (10) especificaram a quantidade de "latas" solicitadas:

\section{[...] determinar que o agravante forneça imediatamente} nove latas/mês de LEITE PREGOMIN à criança (A-2).

Porém ainda que se especifique o número de latas requeridas, trata-se de uma quantidade que terá finitude de poucos meses. Outros 15,3\% (4) não especificaram quantidade, mas referiram que deve ser de acordo com o receituário médico:

Concessão do suplemento alimentar Neocate para V. V. em quantidade compativel com a prescrição estipulada pelos médicos (A-163).

Desta forma, o judiciário atende as necessidades das pessoas de forma recortada ${ }^{(13)}$, pois, ao fornecer apenas a quantidade estipulada ou por um período determinado pelo processo, não é levado em consideração às necessidades futuras da criança, que virão com o seu crescimento e desenvolvimento.

Nas decisões judiciais o profissional nutricionista foi citado em apenas 3,8\% (1) dos documentos, sendo o médico o profissional que ganha destaque quando o magistrado considera a prescrição médica, prova irrefutável na necessidade da pessoa. Esses dados permitem considerar a centralidade e hegemonia da prescrição médica na determinação destas demandas, pois o nutricionista, profissional que se entende responsável pela alimentação e nutrição, foi citado apenas em um documento analisado:

\section{[...] que fora prescrito por médico e nutricionista do Centro de Reabilitação Dom Aquino Corrêa (A-148).}

Em 100\% (26) da demanda por compostos alimentares, eles foram referidos por suas marcas, não contendo informações de suas fórmulas ou indicações de outros compostos alternativos:

forneça ao menor Agravado 20 (vinte) latas do suplemento alimentar NAN ao mês (A-93). 
Neste caso, o composto alimentar é o leite em pó comercializado nos supermercados, do qual existem no mercado diversas marcas que poderiam ser referidas como alternativa, já que não é produzido exclusivamente por uma única empresa. Com isso, fica marcada a presença da indústria na determinação destes compostos no processo judicial, onde a marca "mais lembrada" ou a "mais comercializada" é escolhida pelo profissional, não considerando as demais existentes no mercado.

Esse fato, muitas vezes provém da falta de informação dos operantes do direito, em relação às políticas públicas de saúde e aos aspectos éticos que envolvem a prescrição médica ${ }^{(10)}$. A LEI $n^{\circ} 9.787$, de 10 de fevereiro de 1999, padroniza como devem ser identificados os medicamentos nas prescrições médicas, trazendo essa obrigatoriedade em seu Art. $3^{\circ}$ em que, para compra de medicamentos, as prescrições médicas, no âmbito do SUS, têm obrigação de usar a Denominação Comum Brasileira (DCB), que unifica os nomes dos medicamentos liberados pela ANVISA e disponíveis no Brasil, na sua falta, deve-se usar Denominação Comum Internacional (DCI) ${ }^{(14)}$.

Portanto, devem ser utilizadas demoninações genéricas em todas as prescrições de profissionais autorizados nos serviços públicos, conveniados e contratados no âmbito do SUS. Fica evidente, que isso não foi respeitado nestas decisões, onde sucede a hegemonia da marca Nestlé, que foi citada em 21,4\% (6), seguida pela Support $14,2 \%$ (4) e Abbott 7,1\% (2):

\section{[...] medicamento denominado MODULEN 400g, fabricado pela Nestlé (A-333).}

Em relação ao motivo da demanda (Tabela 3), não foi possível identificar o adoecimento em 17,8\% (5) das decisões por não trazerem informações suficientes; em $10,7 \%$ (3) a doença foi citada de forma inespecífica:
Tabela 3: Motivo da demanda-Adoecimento nas decisões judiciais, Mato Grosso, 2008-2009.

\begin{tabular}{lcc}
\hline \multicolumn{1}{c}{ Adoecimento } & Número de decisões & \% \\
\hline Alergia a lactose & 5 & 17,8 \\
Fenilcetonúria & 2 & 7,1 \\
Paralisia cerebral & 2 & 7,1 \\
Diabetes & 2 & 7,1 \\
Desnutrição & 2 & 7,1 \\
Anorexia & 1 & 3,5 \\
Acidose tubular renal & 1 & 3,5 \\
Sem especificações & & \\
$\quad$ Não especifica a doença & 3 & 10,7 \\
Não é possível identificar & 5 & 17,8 \\
Mais de um adoecimento & 5 & 17,8 \\
\hline \multicolumn{2}{c}{ Total } & $\mathbf{2 8}$ \\
\hline \multicolumn{2}{c}{}
\end{tabular}

[...] anomalia congênita grave (B-273); doença grave e permanente (B-333); portador de doenças alérgicas (B-16).

Em 17,8\% (5) das decisões foi citado mais de um motivo para a demanda e, entre estes, a alergia a lactose, a impossibilidade de aleitamento materno e a falta de recursos do usuário/família se destacaram:

\section{[...] necessita impreterivelmente do fornecimento do Leite} Nan Soy, em razão de seu quadro alérgico ao produto convencional e impossibilidade do aleitamento materno (B-21).

Pessoas acometidas por morbidades, seja qual for, acabam alterando involuntariamente sua alimentação, quer seja por intolerância a determinados alimentos ou até por anorexia ou fadiga demandando, assim, diferentes compostos alimentares. A alimentação é um ato voluntário e consciente, depende totalmente da vontade da pessoa que escolhe o alimento para o seu consumo. A nutrição é um ato involuntário, que termina na absorção dos nutrientes, que são os componentes dos alimentos, muito importantes para a saúde ${ }^{(15)}$.

Por esse motivo, assegurar o direito a uma alimentação e nutrição adequada a toda à população é uma responsabilidade a ser compartilhada por todos os setores governamentais e pela sociedade como um todo. Assim, entende-se que a garantia desse direito requer o empenho do Estado em conciliar ações públicas de diferentes setores e esferas do governo e da sociedade civil. Essas ações dão consequência prática ao direito humano à alimentação e nutrição adequadas ${ }^{(16)}$ :

\section{[...] pois o alimento especial é vital para a vida do agravado} (E-108). 
Quando a população não é contemplada com esse direito, ela torna-se alvo de problemas de saúde relacionados à alimentação; ao ser insuficiente, pode levar a um quadro de desnutrição, que acomete principalmente as crianças, e se expressa pelo baixo peso, sendo evidenciada pelo atraso no crescimento e desenvolvimento e maior vulnerabilidade às infecções ${ }^{(16)}$ :

[...] os gêmeos superem a desnutrição, estando aptos para um desenvolvimento sadio (E-206).

Um problema de saúde relacionado à alimentação, não por falta dela, mas pela intolerância a um componente dos alimentos, é a alergia alimentar, especificamente a alergia à lactose (açúcar predominante do leite), evidenciado em $17,8 \%$ (5) das decisões. Sua causa está relacionada à incapacidade do intestino de digerir e transformar lactose em glicose e galactose, isso resulta da diminuição da atividade de uma enzima chamada lactase, produzida no intestino delgado(17).

Os sujeitos destas decisões judiciais foram nomeados como sendo crianças, mesmo não sendo possível delimitar as idades, sabe-se que a alergia ao leite de vaca é a mais comum na faixa etária pediátrica, com relatos da literatura indicando uma prevalência de entre $2 \%$ e $7,5 \%$ em crianças nos primeiros anos de vida(18):

Dos referidos documentos consta que o agravado é menor de 03 anos e 6 meses, com alergia a leite de vaca [...] (E16).

Рara o tratamento recomenda-se evitar temporariamente leite e produtos lácteos da dieta para cessação dos sintomas, como também incentivar a ingestão de alimentos que contenham cálcio e outras proteínas ${ }^{(17)}$. Considerando que o leite é o primeiro e único alimento do recém-nascido, sendo essencial para o seu crescimento e desenvolvimento, a criança com essa intolerância submetida a uma dieta que restringe o leite, precisará ter adicionados alguns nutrientes à sua alimentação, como o cálcio, que é fundamental para a formação e manutenção da estrutura óssea, sendo necessário o acompanhamento do pediatra ou do nutricionista, para monitorar essa suplementação(16-17).
O aleitamento materno exclusivo nos primeiros seis meses, sem expor a criança a outros tipos de alimentos, dentre outras vantagens, contribui na prevenção de alergias alimentares(19). Porém, quando isso não é possível gera-se uma demanda por tipos de leites específicos. Como no caso da fenilcetonúria (PKU), doença genética, que possui ausência da enzima hepática fenilalanina (Phe) hidroxilase. Por se tratar de uma condição crônica o tratamento é contínuo através de uma dieta com baixo teor de Phe, similar a vegetariana e é necessário o uso de fórmula alimentar medicinal: objetivando o fornecimento de medicação por ser portador de Fenilcetonúria (B-16).

A condição crônica "tem como característica se perdurar no tempo ou ser permanente e impor necessidades renovadas e ampliadas, sendo o seu tratamento dependente de práticas eficazes de cuidado"(13).

Na totalidade das demandas, em que foi possível identificar o adoecimento, tratou-se de condições crônicas, fazendo-se necessário pensar na pontualidade das ações judiciárias, que atendem a uma única necessidade de saúde. Essa pontualidade se expressa na não relação, feita pelo judiciário ao julgar a demanda, com o aumento da necessidade do suplemento alimentar pela criança com o seu desenvolvimento ${ }^{(13)}$.

A condição crônica demanda continuidade de cuidados, e, no caso da mediação jurídica, a pessoa precisará mover nova demanda através de uma ação judiciária para, então, prover cuidados frente às necessidades continuadas e constantemente renovadas ${ }^{(13)}$.

\section{CONCLUSÕES}

A partir das exposições, nota-se que os sujeitos da demanda têm o seu pedido atendido pelo poder judiciário. O direito à saúde, previsto na $C F$, tem se constituído no principal argumento jurídico, e o receituário médico, sua principal prova. A prescrição médica por sua vez, impõe o uso de marcas comerciais em todas as decisões, pois as fórmulas de leites não aparecem em nenhum momento, o que evidencia-se, uma forte predominância da indústria, com hegemonia de certas marcas de compostos alimentares. Isso afirma a necessidade de cumprimento da lei que estabelece a prescrição dos componentes da fórmula, e não a marca comercializada. 
A alergia alimentar em crianças foi o principal motivo da demanda, verifica-se com isso, a necessidade em reforçar ações que promovam o aleitamento materno, bem como estratégias para expandir e fortalecer a política de aleitamento materno e alimentação complementar.

Por fim, considerando a mediação do TJMT frente às condições crônicas de saúde, percebe-se a necessidade de entendimento do campo do direito e da saúde em relação às necessidades das pessoas que vivenciam estas condições, e que demandam cuidados continuados e constantemente renovados, frente às ações de caráter

\section{REFERÊNCIAS}

1. Senado Federal. Constituição 1988. Constituição da República Federativa do Brasil. Brasília (Brasília): Senado Federal; 1988. 2. Lei n. 8080 de 19 de setembro de 1990. Dispõe sobre as condições para a promoção, proteção e recuperação da saúde, a organização e o funcionamento dos serviços correspondentes e das outras providências. Diário Oficial da União; 1990.

3. Ministério da Saúde. Secretaria de Atenção à Saúde. Departamento de Atenção Básica. Portaria № 2.715, de 17 de novembro de 2011 - Atualiza a Política Nacional de Alimentação e Nutrição. Brasília (Brasil): Ministério da Saúde; 2011.

4. Ministério da Saúde. Portaria $n^{\circ} 2.583$, de 10 de outubro de 2007. Define elenco de medicamentos e insumos disponibilizados pelo SUS, nos termos da Lei n 11.347 , de 2006, aos usuários portadores de diabetes mellitus. Diário Oficial da União; 2007.

5. Ministério da Saúde. Conselho Nacional de Saúde. Lei n. 11.347 de 27 de setembro de 2006. Dispõe sobre a distribuição gratuita de medicamentos e materiais necessários à sua aplicação e à monitoração da glicemia capilar aos portadores de diabetes inscritos em programas de educação para diabéticos. Diário Oficial da União; 2006.

6. Sisson MC. Considerações sobre o programa de saúde da família e a promoção de maior equidade na política de saúde. Saúde Sociedade. 2007;16(3): 85-91.

7. Sena RR, Silva KL. Políticas e práticas de saúde rumo à equidade. Rev Esc Enferm USP. 2007;41:771-6.

8. Poupart J, Deslauries JP, Groulx LH, Laperriére A, Mayer R, Pires AP. A pesquisa qualitativa: enfoques epistemológicos e metodológicos. Nasser AC, translator. Petrópolis: Vozes, 2008.

9. Minayo MCS. O desafio do conhecimento: pesquisa qualitativa em saúde. 11 ed. São Paulo: Hucitec, 2008.

10. Gandini JAD, Barione SF, Souza AE. A Judicialização do Direito à Saúde: a obtenção de atendimento médico, medicamentos e insumos terapêuticos por via judicial - critérios e experiências. BD Jur. [Internet]. 2007 [cited 2012 mar 30]. Available from: http://bdjur.stj.gov.br/dspace/handle/2011/16694.

11. Ribas CRP, Teixeira CRS, Oliveira VA, Martins TA, Mendes KDS, Andrade NHS et al. Incidentes críticos no processo de ensinoaprendizagem em diabetes na perspectiva da equipe multiprofissional de saúde. Rev. Eletr. Enf. [Internet]. 2008 [cited 2012 mar 30];10(3):747-55. Available from: http://www.fen.ufg.br/revista/v10/n3/v10n3a20.htm.

12. Ministério da Saúde. Portaria n 371 de 04 de março de 2002. Diário Oficial da União; 2002.

13. Araújo LFS, Bellato R, Corrêa GHLZT, Mufato LF, Nepomuceno MAS. Análise da demanda do direito à saúde e as possibilidades de mediação pelo tribunal de justiça de Mato Grosso. In: Pinheiro R, Martins PH, editors. Usuários, mediações e integralidade em saúde. Rio de Janeiro: UERJ/REDE SIRIUS/CBC; 2011. p.185-192

14. Lei $n^{\circ} 9.787$, de 10 de fevereiro de 1999 . Altera a Lei $n^{\circ} 6.360$, de 23 de setembro de 1976, que dispõe sobre a vigilância sanitária, pontual das decisões do judiciário, o que pouco têm contribuído na efetivação da equidade e integralidade do cuidado em saúde. É preciso que ocorra a melhoria na relação entre estes campos, da saúde e do direito, pois os poderes devem ser equilibrados com diálogo, e os gestores possuem papel fundamental para desencadear este processo.

Observa-se, também, que os protocolos e leis precisam adequar-se as necessidades de saúde das pessoas, e não o contrário; e fazer cumprir as garantias de direito consubstanciadas na CF é ainda um grande desafio para os gestores.

estabelece o medicamento genérico, dispõe sobre a utilização de nomes genéricos em produtos farmacêuticos e dá outras providências. Diário Oficial da União;1999.

15. Ministério da Educação. Secretaria de Educação Básica. Modulo 10: Alimentação e nutrição no Brasil l. Brasília: Universidade de Brasília, 2007.

16. Ministério da Saúde. Secretaria de Atenção à Saúde. Coordenação-Geral da Política de Alimentação e Nutrição. Guia alimentar para a população brasileira: Promovendo a alimentação saudável. Brasília: Ministério da Saúde, 2008.

17. Mattar R, Mazo DFC. Intolerância à lactose: mudança de paradigmas com a biologia molecular. Rev Assoc Med Bras. 2010;56(2):230-6.

18. Pereira PB, Silva CP. Alergia a proteína do leite de vaca em crianças: repercussão da dieta de exclusão e dieta substitutiva sobre o estado nutricional. Pediatria (São Paulo). 2010;30(2):100-6. 19. Batista GS, Freitas AMF, Haack A. Alergia alimentar e desmame precoce: uma revisão do ponto de vista nutricional. Com. Ciências Saúde. 2009;20(4):351-60

Artigo recebido em 09.11.2010. Aprovado para publicação em 13.03.2012. Artigo publicado em 30.03.2012. 